\title{
A review of the development of tumor vasculature and its effects on the tumor microenvironment
}

\author{
Jake C Forster ${ }^{1,2}$ \\ Wendy M Harriss-Phillips ${ }^{1,2}$ \\ Michael JJ Douglass ${ }^{1,2}$ \\ Eva Bezak',3 \\ 'Department of Physics, University \\ of Adelaide, ${ }^{2}$ Department of Medical \\ Physics, Royal Adelaide Hospital, \\ ${ }^{3}$ Sansom Institute for Health Research \\ and the School of Health Sciences, \\ University of South Australia, \\ Adelaide, SA, Australia
}

This article was published in the following Dove Press journal:

Hypoxia

II April 2017

Number of times this article has been viewed

Background: The imbalance of angiogenic regulators in tumors drives tumor angiogenesis and causes the vasculature to develop much differently in tumors than in normal tissue. There are several cancer therapy techniques currently being used and developed that target the tumor vasculature for the treatment of solid tumors. This article reviews the aspects of the tumor vasculature that are relevant to most cancer therapies but particularly to vascular targeting techniques. Materials and methods: We conducted a review of identified experiments in which tumors were transplanted into animals to study the development of the tumor vasculature with tumor growth. Quantitative vasculature morphology data for spontaneous human head and neck cancers are reviewed. Parameters assessed include the highest microvascular density (h-MVD) and the relative vascular volume (RVV). The effects of the vasculature on the tumor microenvironment are discussed, including the distributions of hypoxia and proliferation.

Results: Data for the h-MVD and RVV in head and neck cancers are highly varied, partly due to methodological differences. However, it is clear that the cancers are typically more vascularized than the corresponding normal tissue. The commonly observed chronic hypoxia and acute hypoxia in these tumors are due to high intratumor heterogeneity in MVD and lower than normal blood oxygenation levels through the abnormally developed tumor vasculature. Hypoxic regions are associated with decreased cell proliferation.

Conclusion: The morphology of the vasculature strongly influences the tumor microenvironment, with important implications for tumor response to medical intervention such as radiotherapy. Quantitative vasculature morphology data herein may be used to inform computational models that simulate the spatial tumor vasculature. Such models may play an important role in exploring and optimizing vascular targeting cancer therapies.

Keywords: cancer, head and neck, vasculature morphology, hypoxia, radiotherapy response

\section{Introduction}

In cancer therapy, techniques continue to be used and developed that target the tumor vasculature for the treatment of solid tumors. The tumor vasculature is essential for keeping the tumor alive and facilitating its growth. Tumor cells must be within a certain distance of a perfused blood vessel to receive sufficient oxygen and nutrients to survive and proliferate. It is for this reason that solid tumors must become angiogenic and recruit their own vasculature to grow beyond $1-2 \mathrm{~mm}$ in diameter. ${ }^{1}$

Various approaches of vascular targeting are currently being explored, including antiangiogenic agents that disrupt the formation of new blood vessels and vascular targeting agents that shut down the existing tumor blood flow. ${ }^{2}$ In the radiotherapy domain, the tumor response to high doses of radiation includes widespread damages
Correspondence: Jake C Forster Department of Physics, University of Adelaide, Physics Building, Room GI6, North Terrace, Adelaide, SA 5005, Australia

Tel +61883135996

Fax +61883134380

Email jake.forster@adelaide.edu.au 
to the vasculature. ${ }^{3,4}$ High dose per fraction treatments such as stereotactic body radiation therapy (SBRT) are finding increasing clinical use worldwide for small- to mediumsized primary and metastatic disease, ${ }^{5,6}$ although the extent to which vascular damage is responsible for the success of SBRT is not clear. ${ }^{7}$ There is also tumor antivascular alpha therapy (TAVAT), in which alpha-emitting radionuclides are delivered to the tumor vasculature to disrupt the tumor vessels. ${ }^{8}$

The tumor vasculature plays an indirect role in other cancer treatment modalities. In chemotherapy, the tumor vasculature is relied upon to deliver the drugs to the tumor cells. The tumor vasculature performs the same role in the technique of tumor radiosensitization using nanoparticles such as gold. ${ }^{9}$ There is also interest in radiosensitizing the tumor vessels themselves - as opposed to the tumor cells - by irradiating shortly after ingestion of nanoparticles while they are still concentrated in the tumor vasculature. ${ }^{10}$

With several treatment modalities currently being explored that target the tumor vasculature primarily or secondarily, a topical review is presented herein on the tumor vasculature, focusing on the aspects that are relevant to most cancer therapies and especially to vascular targeting techniques. The first part of this article is a review of the process of tumor vascularization and how the vasculature develops during tumor growth. Experiments are revisited in which tumors were transplanted into rats and mice for the purpose of studying the development of the tumor vasculature. In some experiments, transparent chambers were used to observe changes to the tumor vasculature in real time, while others grew tumors to different sizes and then compared the vasculature between them. The vasculature morphology in tumors, like in normal tissue, can be described quantitatively with parameters such as the average vessel diameter, the vascular density, and the relative vascular volume (RVV). The second part of this article provides a compilation of tumor vasculature morphology data from the literature for spontaneous head and neck cancers in humans. Head and neck cancers were chosen because they are often poorly oxygenated. ${ }^{11}$ Finally, there is a review of the effects of the tumor vasculature on the tumor microenvironment. More recently, this has been explored by staining tumor sections with markers for blood vessels, perfusion, hypoxia, and proliferation. Studies of head and neck cancers were exemplary.

The scope of the biology content in this review is intended for a medical physics audience. It is written from a historical perspective, discussing the key findings made. Quantitative vasculature morphology data are emphasized, which may be used to inform computational models that simulate the spatial tumor vasculature. Such models may play an important role in exploring and optimizing vascular targeting cancer therapies.

\section{Materials and methods}

The following search strategy and selection criteria were used. Three separate searches were performed using the PubMed database, one for each section of the review. Each search was across all years, and only publications in English were considered.

For the first section, studies of the development of the vasculature in tumor transplants were found by a search of the following keywords: "tumor AND vasculature AND transplant AND quantitative". To be considered, publications had to present findings pertaining to the morphology or functionality of the vasculature at different stages of tumor growth. From the search results and references therein, 57 such publications were found, 15 of which were deemed representative and were discussed in the review.

In the second section, to find vasculature morphology data for spontaneous human cancers of the head and neck, a search was conducted using the keywords: "tumor AND vasculature AND human AND (oral OR laryngeal OR tongue OR pharyngeal OR salivary OR cheek) AND ([vessel density] OR [vessel volume] OR [vessel diameter])". Importantly, due to the large variation in measurements from using different methodologies, publications were only included if they reported measurements on the corresponding normal tissue and on the cancer. In addition, measurements had to be presented as mean \pm standard deviation, for vessel densities, there had to be sufficient information to convert the value to $\mathrm{mm}^{-2}$ and finally a reasonable sample size was required. Of the 87 publications, 9 met these criteria. The data were tabulated for comparison of measurements between different groups.

For the third section regarding the effects of the tumor vasculature on the tumor microenvironment, a search was conducted using the following keywords: "tumor AND vasculature AND distance AND (proliferation OR hypoxia OR necrosis)". Nine publications were selected for discussion from the search results and references therein. Aside from historically significant publications, the most insightful studies were those conducted on head and neck cancers.

\section{Results and discussion Development of tumor vasculature with tumor growth}

The first group to quantitate changes in the tumor vasculature morphology during tumor growth was Algire and 
Chalkley. ${ }^{12}$ They transplanted tumors of mammary gland carcinoma and sarcoma 37 into transparent skin flap chambers in mice to grow in the subcutaneous connective tissue. The tumors became vascularized by eliciting the sprouting of new capillaries from the vessels in the surrounding host tissue. This process is called angiogenesis. ${ }^{13}$ Angiogenesis also occurred with implants of subcutaneous tissue and at the site of a wound. However, for tumors, it occurred 3 days after implantation, whereas it began 6 days after implantation of subcutaneous tissue or the infliction of a wound. The tumors only increased in size once they became pervaded by capillaries. The tumor vascularity increased, and angiogenesis continued to occur at the tumor edge to facilitate the increasing tumor size. The RVV, which was the relative proportion of the tumor area in the chamber covered by blood vessels, was measured daily using a method devised by Chalkley. ${ }^{14}$ Briefly, an eyepiece graticule is randomly placed several times, and the proportion of coincidences with vessels yields the RVV. The RVV increased and reached $50 \%$ only 7 days after implantation and maintained this level thereafter, which was twice the value in control chambers containing normal subcutaneous tissue. The tumor vasculature was a sinusoid-like plexus of vessels with large marginal draining vessels. There was no evidence that the new tumor vessels differentiated into venules or arterioles. They retained their capillary-like structure, having walls that contained only a single layer of endothelium, but their diameters were much larger than the capillaries in normal subcutaneous tissue. Such observations revealed that the vasculature in tumors is chaotic compared to that in normal tissue (Figure 1).

The formation of the tumor vasculature was described in more detail by Eddy and Casarett. ${ }^{16}$ They studied the development of the vasculature in tumors of a malignant neurilemmoma of the Syrian hamster as they grew in a transparent cheek pouch chamber. After tumor implantation, the veins and venules in the surrounding host tissue dilated and become tortuous. The arterial vessels were largely unaffected in comparison. The capillary sprouts of angiogenesis were seen to originate from the host venous vessels, although the magnitude of this activity may have obscured a similar activity in the host capillary bed. The capillary sprouts elongated and anastomosed with each other to establish a capillary-like network in the tumor. As soon as a tumor capillary anastomosed with the arterial end of a host capillary, the direction of blood flow changed so that the host arterial supply flowed through the tumor capillary network to the host venous system. Anastomoses between the tumor capillaries and the host arterioles were seemingly random and occasionally resulted in inefficient blood distribution. For example, a single short capillary could conduct blood from a host arteriole directly to a wide capillary-like vessel, which drained to the tumor perimeter. As the tumor increased in size, the host venous vessels were remodeled and pushed away until finally being incorporated into the tumor. In contrast, the host arterial vessels remained in about the same location as the tumor grew around them. The tumor vessels maintained a capillary-like structure, including a number that progressively dilated and reached diameters as large as $200 \mu \mathrm{m}$ in some cases (capillaries normally have diameters less than $12 \mu \mathrm{m}$ ). In the later stages of tumor growth, it was apparent that some vessels had become occluded. Blood flow was restored if the chamber walls were separated by even a fraction of a millimeter.

Yamaura and Sato ${ }^{17}$ further quantitated the development of the tumor vasculature morphology in tumors of rat ascites hepatoma growing in transparent chambers. At various days after tumor implantation, they measured the frequency distribution of vessel diameters and the RVV using Chalkley's method in the whole chamber. They also used these measurements to calculate the vascular length and surface area per unit volume of tissue. Tumor angiogenesis began after 3 to 5 days. The sprouting of capillaries resulted in an increase in the proportion of vessels with diameters less than $10 \mu \mathrm{m}$

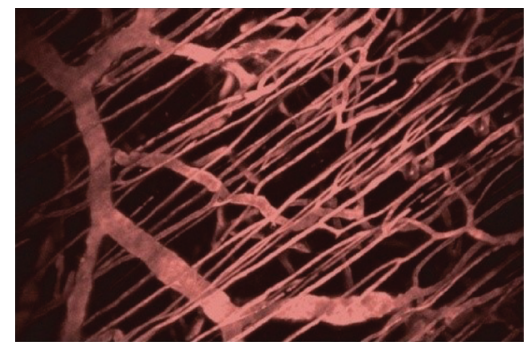

Normal tissue

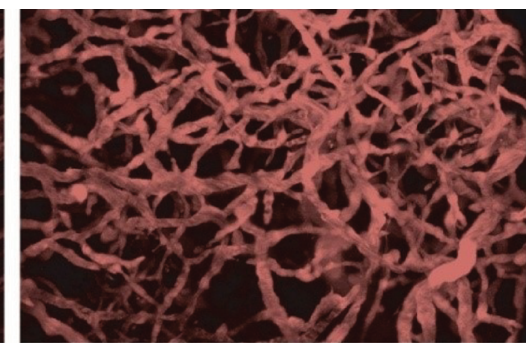

Tumor

Figure I Organized vasculature in normal tissue contrasted with chaotic vasculature in tumors.

Note: Adapted with permission from Macmillan Publishers Ltd.: Nature Medicine, Jain RK, Molecular regulation of vessel maturation, 2003;9(6):685-693, ${ }^{15}$ copyright (2003). 
from 40 to $70 \%$. The vascular length increased from 30 to $160 \mathrm{~cm} / \mathrm{mm}^{3}$, the vascular surface area increased from 20 to $63 \mathrm{~mm}^{2} / \mathrm{mm}^{3}$, and the RVV increased from 20 to $50 \%$. On day 10 , the tumor capillaries began to dilate, causing the frequency distribution of vessel diameters to become low and wide. This was associated with decreases in the vascular length and surface area, but the RVV was unchanged. There were changes to the host arterial vessels around this time. Their walls became thin and ragged, their lumina widened at branching sites, they took on a zigzag pattern and vasomotion eventually disappeared. After 14 days, necrosis appeared near the center of the tumor and spread outward, seemingly due to prolonged vessel occlusion. The smallest vessels were the first to close, resulting in cords of viable tissue surrounding the remaining larger vessels, beyond which there was necrosis. Eventually, even the widest vessels were forced shut and the tumor became completely necrotic. Necrosis was associated with the disappearance of blood vessels and thus coincided with decreases in the vascular length, vascular surface area, and RVV to zero.

It is worth briefly mentioning the findings of a few other experiments in which tumors were grown in transparent chambers. Peters et $\mathrm{al}^{18}$ observed that in normal tissue, the capillary perfusion was uniform and orderly. Conversely, in a mammary adenocarcinoma, red blood cells were often densely packed and slowly squeezed single file through windy capillaries. Capillaries could alternate between very fast and very slow perfusion. Boucher et a ${ }^{19}$ demonstrated that the interstitial fluid pressure increased over time in human colon adenocarcinoma and mouse mammary adenocarcinoma growing in a skin fold chamber in mice. Endrich et $\mathrm{al}^{20}$ found that the mean blood flow to amelantotic melanoma growing in a chamber decreased from $40.4 \mathrm{~mL} / \mathrm{min} / 100 \mathrm{~g}$ on day 4 to $21.1 \mathrm{~mL} / \mathrm{min} / 100 \mathrm{~g}$ on day 12 . Central necrosis appeared in these tumors after just 5 days. Vajkoczy et al ${ }^{21}$ showed for gliomas growing in a skin fold chamber in mice that the onset of central necrosis on day 22 coincided with a significant decrease in the vessel perfusion index in the central region of the tumor compared to that in the marginal region. Each of these findings suggests that blood vessels may become occluded during tumor growth in chambers, which if prolonged could cause necrosis from blood stasis.

The transparent chamber technique allowed for observation of the development of the tumor vasculature in real time. In particular, it provided unique insight into the process of tumor vascularization as discussed earlier. However, this technique has limitations. Recall in the experiment by Eddy and Casarett, ${ }^{16}$ it was shown that permanent and widespread vessel occlusion can occur in tumors that grow within the confines of a chamber due to pressure from the chamber itself. This quickly leads to massive necrosis, making it difficult to study the development of the tumor vasculature after the earliest stages of growth. Therefore, the discussion now moves to experiments that grew tumor transplants to different sizes without being confined to a chamber, then internally examined them to view the state of the tumor vasculature at various stages of growth.

Although prolonged vessel occlusion and thus necrosis may be produced artificially in chamber experiments, these processes occur naturally in tumors as well. Large interstitial pressures develop in tumors due to a combination of the high tumor cell density $\left(10^{8}-10^{9}\right.$ cells $\left./ \mathrm{cm}^{3}\right)$, high blood vessel permeability, and poor lymphatics. ${ }^{22}$ Goldacre and Sylven $^{23}$ found that for various unicentric mouse and rat tumors transplanted subcutaneously or intramuscularly, central necrosis appeared when tumors reached a diameter of $1 \mathrm{~cm}$. It was found by injection of a dye that there was no blood flow to the necrotic zone, but there were blood vessels in the necrotic zone that contained undamaged red blood cells. These findings indicated that vessel occlusion resulting in blood stasis was responsible for the central necrosis. For tumor transplants of rat fibrosarcoma in which necrosis tended to develop centrally, Tozer et $\mathrm{al}^{24}$ showed that the mean blood flow $(\mathrm{mL} / \mathrm{min} / 100 \mathrm{~g})$ decreased with increasing tumor size. Furthermore, the blood flow was constant in the tumor periphery, it was in the center that it decreased. In all but the smallest tumors, blood flow was lower in the center than the periphery, even when only considering viable tissue.

Tannock and Steel ${ }^{25}$ found that the relative necrotic volume (the relative proportion of the tumor section covered by necrosis, measured using Chalkley's method) in equatorial sections of transplanted rat mammary tumors increased with tumor weight from $0 \%$ at $0.5 \mathrm{~g}$ to $50 \%$ at $10 \mathrm{~g}$. By labeling red blood cells with chromium-51 and observing that only a small fraction of the red blood cells in necrotic regions were labeled compared to that in viable regions, it was concluded that the cause of necrosis was again stasis in tumor blood vessels caused by vessel occlusion.

Fallowfield ${ }^{26}$ reported that for murine melanoma B16 and human melanoma Mel-mo transplanted subcutaneously in mice, the relative perfused vascular volume (as determined by staining with Hoechst 33342) in all tumor tissue, both viable and necrotic, decreased with the logarithm of tumor weight, while the relative necrotic volume increased with the logarithm of tumor weight. These relationships suggest that necrosis appeared when the blood vessels became occluded. 
In Mel-mo tumors weighing between 37 and $2050 \mathrm{mg}$, the relative perfused vascular volume decreased from 12.6 to $4.1 \%$ and the relative necrotic volume increased from 24 to $48.8 \%$. In B16 tumors weighing between 80 and $3612 \mathrm{mg}$, the relative perfused vascular volume decreased from 20 to $8.7 \%$ and the relative necrotic volume increased from 2.8 to $30 \%$.

Different tumor types can elicit entirely different patterns of vasculature from the host subcutaneous tissue. Rubin and Casarett ${ }^{27}$ used angiography to study the development of the vasculature in tumors of Walker carcinosarcoma and Murphy lymphosarcoma transplanted into rats. Walker carcinosarcoma induced "peripheral vascularization", which consisted of vessels corkscrewing radially into the tumor. Once these tumors reached 1.5 to $3 \mathrm{~cm}$ in diameter, central necrosis appeared and the radial vessels abruptly terminated at the necrotic edge. Murphy lymphosarcoma induced a contrasting pattern of "central vascularization". Major vessels penetrated into the tumor center and formed an axial trunk from which smaller vessels branched out to the periphery in an arborescent fashion. Central necrosis did not develop in these tumors.

Gliomas induce a distinct vasculature that differs systematically from the tumor center to periphery. The development of the glioma vasculature was best described by Deane and Lantos $^{28}$ who induced gliomas in rats by intracerebral injection of neoplastic glial cells, but similar findings have been reported for gliomas growing subcutaneously. ${ }^{21}$ The gliomas remained avascular to sizes up to $1 \mathrm{~mm}$ in diameter. In larger tumors up to $4 \mathrm{~mm}$ in diameter, the core remained avascular and occasionally developed necrosis, while at the tumor periphery, there were capillary buds and capillaries up to $5 \mu \mathrm{m}$ in diameter corresponding to early angiogenesis. In tumors larger than $4 \mathrm{~mm}$, there was a third zone in between the central avascular necrotic zone and the peripheral zone of early angiogenesis. This intermediate zone contained tortuous vessels with diameters ranging from 3 to $40 \mu \mathrm{m}$. The wider vessels were unusually large sinusoidal capillaries lined by up to 15 endothelial cells. It was deemed that the vasculature in the intermediate zone was in the "late vascular stage".

Perhaps the most quantitative study of the development of tumor vasculature morphology was conducted by Vogel. ${ }^{29}$ Tumors of mammary adenocarcinoma $72 \mathrm{j}$ were transplanted subcutaneously in mice and permitted to grow for 6,17 , or 23 days to produce a range of tumor weights from 5 to $2700 \mathrm{mg}$. Necrotic regions were randomly scattered throughout tumors weighing more than $300 \mathrm{mg}$ and occupied between 5 and $15 \%$ of the tumor cross section. Vessels were stained by injection of India ink so the vasculature morphology was only measured in viable regions. The vasculature morphology was quantitated by measuring the frequency distribution of vessel diameters and the RVV using Chalkley's method. The vascular length and surface area per unit volume of tissue were also calculated. Viable regions in the center showed no significant differences in vasculature morphology compared to viable regions in the periphery. In the smallest tumors between 5 and $30 \mathrm{mg}$, vascular length was $820 \mathrm{~mm} / \mathrm{mm}^{3}$ and vascular surface area was $34 \mathrm{~mm}^{2} /$ $\mathrm{mm}^{3}$. In the largest tumors weighing between 1.1 and $2.7 \mathrm{~g}$, the vascular length and surface area in viable tissue were drastically reduced. The vascular length was $47 \mathrm{~mm} / \mathrm{mm}^{3}$, and the vascular surface area was $7 \mathrm{~mm}^{2} / \mathrm{mm}^{3}$. The RVV increased only slightly from 16 to $18 \%$ in the viable tissue from the smallest tumors to the largest. The frequency distribution of vessel diameters revealed that $70 \%$ of vessels had a diameter less than $12 \mu \mathrm{m}$ for tumors weighing between 5 and $30 \mathrm{mg}$, but as the tumors increased in size, there was a familiar widening and flattening of the distribution. In tumors weighing between 1.1 and $2.7 \mathrm{~g}$, only $27 \%$ of the vessels had a diameter less than $12 \mu \mathrm{m}$. Vogel reported that tumor growth was accompanied by an increase in sinusoidal areas compared to capillary areas. Typical capillary areas had $97 \%$ of vessel diameters less than $12 \mu \mathrm{m}$, an RVV of $12 \%$, an average vessel diameter of $6.7 \mu \mathrm{m}$, a vascular length of $1700 \mathrm{~mm} / \mathrm{mm}^{2}$, and a vascular surface area of $45 \mathrm{~mm}^{2} / \mathrm{mm}^{3}$. Contrastingly, sinusoidal areas had $11 \%$ of vessel diameters less than $12 \mu \mathrm{m}$, an RVV of $32 \%$, an average vessel diameter of $53 \mu \mathrm{m}$, a vascular length of $50 \mathrm{~mm} / \mathrm{mm}^{3}$, and a vascular surface area of $11 \mathrm{~mm}^{2} / \mathrm{mm}^{3}$.

A similar experiment was conducted by Hilmas and Gillette $^{30}$ on mouse mammary carcinoma grown in gastrocnemius muscle. Tumors ranged between $4 \mathrm{~mm}$ in diameter (volume $35 \mathrm{~mm}^{3}$ ) and $14 \mathrm{~mm}$ in diameter (volume $1500 \mathrm{~mm}^{3}$ ). Again vessels were stained by injection of a contrast agent, in this case colloidal carbon, and the vasculature morphology was quantitated in the viable tissue. The vascular length decreased rapidly from 850 to $350 \mathrm{~mm} / \mathrm{mm}^{3}$ with increasing tumor volume between 35 and $100 \mathrm{~mm}^{3}$. In tumors larger than $500 \mathrm{~mm}^{3}$, the vascular length was $150 \mathrm{~mm} / \mathrm{mm}^{3}$ or less. The vascular surface area was $26.5 \mathrm{~mm}^{2} / \mathrm{mm}^{3}$ in the smallest tumors and $15 \mathrm{~mm}^{2} / \mathrm{mm}^{3}$ or less for tumor volumes of $500 \mathrm{~mm}^{3}$ or greater. An increase in the average vessel diameter was again observed with increasing tumor size. The RVV in viable tissue was a constant $17 \%$ for all tumor sizes. The relative necrotic volume was less than $5 \%$ for tumor volumes of $35 \mathrm{~mm}^{3}$ and increased to over $40 \%$ in tumors with volumes over $1500 \mathrm{~mm}^{3}$. 
In summary, tumors become vascularized by inducing angiogenesis in the veins, venules, and capillaries of the host tissue. Capillaries sprout toward the tumor and anastomose with each other and the host vessels to form a capillary network through the tumor. Angiogenesis continues to occur beyond the tumor periphery to facilitate its increase in size. The host venous vessels are pushed away and remodeled before being incorporating into the growing tumor, while the patterns of the arterial vessels are unchanged as they are incorporated. The tumor capillaries develop abnormally. They dilate and become tortuous while retaining their capillary-like structure and not properly differentiating into arterials and venules. Associated with these changes are decreases in the vascular length and vascular surface area per unit volume of tissue but the RVV remains about the same. The host vessels that become incorporated in the tumor become disfigured too. They dilate and the arterial vessels become thin and ragged and eventually lose vasomotion. The tortuosity of tumor vessels causes vessel perfusion to fluctuate. When tumors become larger, the interstitial fluid pressure can become so great that small vessels become permanently occluded. This leads to blood stasis and the formation of necrotic regions, typically near the tumor center.

It must be noted that these observations are from tumors growing in rats and mice (and generally in the subcutaneous tissue), since only in such animal models has the development of tumor vasculature been closely observed (for ethical and practical reasons). However, it is reasonable to assume that the development of vasculature in spontaneous human tumors shares similarities with the development in animal models.

\section{Vasculature morphology in spontaneous human tumors}

In the past few decades, the vasculature morphology has been quantitated in spontaneous tumors presenting in human patients. This has typically been done by staining the blood vessels in resected specimens using a marker such as von Willebrand factor (vWF), CD34, or CD31. A compilation of the vasculature morphology data from the literature for various head and neck cancers is presented in Table 1. There are six publications for squamous cell carcinoma (SCC) of the oral cavity, two for laryngeal SCC and one for mucoepidermoid carcinoma of the salivary glands. Vasculature morphology parameters include the highest microvascular density (h-MVD), the RVV, and the mean vessel diameter. For every measurement on carcinoma, the measurement on the corresponding normal tissue is also presented. Measurements on dysplasia were included too. The table contains a description of the method used for each measurement.

There is usually large intratumoral heterogeneity in the MVD. For example, Wijffels et $\mathrm{al}^{31}$ found that for various human head and neck SCCs, the values for h-MVD were a factor of 1.5 to 6 times higher than the vascular density across the whole tumor section, referred to as the average MVD (a-MVD). Most groups ${ }^{32-39}$ report on the h-MVD. They do so by staining vessels and measuring the vascular density in the most vascularized areas or "hotspots" in the tumor, an approach pioneered by Weidner et al. ${ }^{40}$ The findings in the table demonstrate that for oral SCC, laryngeal SCC, and mucoepidermoid carcinoma of salivary glands, the h-MVD is significantly higher in carcinoma than in the corresponding normal tissue, i.e., tumors contain regions that are more vascularized than anywhere in the normal tissue. Further, a significant increase from normal to dysplasia was found by Pazouki et al, ${ }^{32}$ Pignataro et al, ${ }^{34}$ Shieh et al, ${ }^{35}$ and Mohtasham et $\mathrm{al}^{39}$ but not by Li et al. ${ }^{36}$ From dysplasia to cancer, Li et $\mathrm{al}^{36}$ and Mohtasham et $\mathrm{al}^{39}$ found a significant increase, while Pazouki et al, ${ }^{32}$ Pignataro et al, ${ }^{34}$ and Shieh et $\mathrm{al}^{35}$ did not.

There is enormous variation in the values of h-MVD for oral SCC presented by different groups. On opposite extremes, Mohtasham et $\mathrm{al}^{39}$ reported a value of $57.8 \pm 10.8 \mathrm{~mm}^{-2}$, while Sharma et $\mathrm{al}^{38}$ found it to be $240.53 \pm 92.3 \mathrm{~mm}^{-2}$. Elsewhere, Davey et $\mathrm{al}^{41}$ reported a median h-MVD of over $1000 \mathrm{~mm}^{-2}$ (and a median of $\sim 400 \mathrm{~mm}^{-2}$ for normal tissue). Schor et $\mathrm{al}^{42}$ demonstrated that measurements of h-MVD are highly subject to the methodology used, including the staining factor, the pretreatment, and the size of the subset area. There is also variation due to interobserver bias. For this reason, it was essential that normal tissue values be provided to serve as a reference point for the measurement on cancer.

The data also indicate that progression of oral SCC is accompanied by increasing RVV, which means tumors are overall more vascularized than normal tissue. This should also be reflected in the parameter a-MVD, but unfortunately there are limited data available. Davey et $\mathrm{al}^{41}$ reported that the a-MVD was significantly higher $(p=0.01)$ in oral SCC than in normal oral mucosa for six specimens when staining vessels with vWF. Nevertheless, given the high degree of intratumor heterogeneity in vascularity, there can still be regions of a tumor, in which the vascularity is comparable to or even less than that in normal tissue.

Li et $\mathrm{al}^{36}$ commented that for oral SCC, high concentrations of vascularization were most commonly found at the 
Table I Vasculature morphology data for spontaneous human head and neck cancers

\begin{tabular}{|c|c|c|c|c|}
\hline Reference (year) & Cancer type & Number of specimens & Method & Measurements \\
\hline Pazouki et al ${ }^{12}$ (1997) & Oral SCC & $\begin{array}{l}\text { I6 of normal oral } \\
\text { mucosa, } 30 \text { of dysplasia } \\
\text { ( } 10 \text { mild, } 9 \text { moderate, } \\
\text { and II severe), and } \\
30 \text { of cancer (I4 } \\
\text { early and I } 6 \text { late) }\end{array}$ & $\begin{array}{l}\text { Vessels were stained } \\
\text { for vWF, h-MVD was } \\
\text { measured using the } \\
\text { hotspot method and } \\
\text { RVV was measured } \\
\text { using Chalkley's } \\
\text { method }\end{array}$ & $\begin{array}{l}\text { h-MVD }\left(\mathrm{mm}^{-2}\right) \text { : normal } 88 \pm 35 \text {, } \\
\text { severe dysplasia } 164 \pm 58, * \text { and late } \\
\text { SCC I } 48 \pm 53^{*} \\
\text { RVV (\%): normal } 3.7 \% \pm 0.5 \% \text {, } \\
\text { increased linearly with severity of } \\
\text { dysplasia, and SCC to } 10.0 \% \pm 2.5 \% \\
\text { for late SCC* (values for RVV were } \\
\text { taken by reading off a graph) }\end{array}$ \\
\hline $\begin{array}{l}\text { Sawatsubashi et al }{ }^{33} \\
(2000)\end{array}$ & Laryngeal SCC & $\begin{array}{l}10 \text { of normal, } 54 \text { of } \\
\text { invasive cancer }\end{array}$ & $\begin{array}{l}\text { Vessels were stained } \\
\text { for CD34, and h-MVD } \\
\text { was measured using } \\
\text { the hotspot method }\end{array}$ & $\begin{array}{l}\text { h-MVD }\left(\mathrm{mm}^{-2}\right) \text { : normal } 21.67 \pm 3.00 \\
\text { and cancer } 37.34 \pm 2.64^{*}\end{array}$ \\
\hline Pignataro et al ${ }^{34}$ (200I) & Laryngeal SCC & $\begin{array}{l}20 \text { of normal mucosa, } \\
20 \text { of dysplasia, and } \\
20 \text { of infiltrating } \\
\text { carcinoma }\end{array}$ & $\begin{array}{l}\text { Vessels were stained } \\
\text { for CD } 34 \text {, and h-MVD } \\
\text { was measured using } \\
\text { the hotspot method }\end{array}$ & $\begin{array}{l}\text { h-MVD }\left(\mathrm{mm}^{-2}\right) \text { : normal } 35.1 \pm \mathrm{I} I .5 \\
\text { dysplasia } 60.9 \pm 19.8, * \text { and cancer } \\
74.8 \pm 19.0^{*}\end{array}$ \\
\hline Shieh et $\mathrm{al}^{35}(2004)$ & Oral SCC & $\begin{array}{l}12 \text { of normal mucosa, } \\
28 \text { of dysplasia, and } \\
50 \text { of } \mathrm{T} 2 \text { cancer }\end{array}$ & $\begin{array}{l}\text { Vessels were stained } \\
\text { for CD34, and h-MVD } \\
\text { was measured using } \\
\text { the hotspot method }\end{array}$ & $\begin{array}{l}\text { h-MVD }\left(\mathrm{mm}^{-2}\right) \text { : normal } 84 \pm 2 \mathrm{I} \text {, } \\
\text { dysplasia } 2 \mathrm{I} 2 \pm 56, * \text { cancer } \\
\text { intratumoral } 226 \pm 50, * \text { and cancer } \\
\text { peritumoral } 240 \pm 58^{*}\end{array}$ \\
\hline Li et $\mathrm{al}^{36}(2005)$ & Oral SCC & $\begin{array}{l}12 \text { of normal mucosa, } \\
26 \text { of mild dysplasia, } \\
16 \text { of moderate dysplasia, } \\
10 \text { of severe dysplasia, } \\
\text { and } 98 \text { of cancer }\end{array}$ & $\begin{array}{l}\text { Vessels were stained } \\
\text { for CD3I, and h-MVD } \\
\text { was measured using } \\
\text { the hotspot method }\end{array}$ & $\begin{array}{l}\text { h-MVD }\left(\mathrm{mm}^{-2}\right) \text { : normal } 31.0 \pm 13.4 \text {, } \\
\text { mild dysplasia } 37.4 \pm 10.8 \text {, moderate } \\
\text { dysplasia } 42.1 \pm 23.8 \text {, severe dysplasia } \\
48.1 \pm 19.6 \text {, and cancer } 79.6 \pm 38.2^{*}\end{array}$ \\
\hline Amelink et al ${ }^{44}(2008)$ & Oral SCC & $\begin{array}{l}16+\text { of normal mucosa } \\
\text { and } 24+\text { of cancer }\end{array}$ & $\begin{array}{l}\text { Noninvasive } \\
\text { differential path-length } \\
\text { spectroscopy in vivo }\end{array}$ & $\begin{array}{l}\text { Mean vessel diameter }(\mu \mathrm{m}) \text { : normal } \\
24 \pm 14 \text { and cancer } 25 \pm 12 \\
\mathrm{RVV}(\%) \text { : normal } 1.0 \pm 0.9 \text { and cancer } \\
2.2 \pm 2.3^{*}\end{array}$ \\
\hline Shieh et $\mathrm{al}^{37}(2009)$ & $\begin{array}{l}\text { Mucoepidermoid } \\
\text { carcinoma of } \\
\text { salivary glands }\end{array}$ & $\begin{array}{l}35 \text { of normal tissue and } \\
35 \text { of cancer }\end{array}$ & $\begin{array}{l}\text { Vessels were stained } \\
\text { for CD34, and } \\
\text { h-MVD was measured } \\
\text { using the hotspot } \\
\text { method }\end{array}$ & $\begin{array}{l}\text { h-MVD }\left(\mathrm{mm}^{-2}\right) \text { : normal } 18.7 \pm 5.2 \text { and } \\
\text { cancer intratumoral } 63.9 \pm 23.2^{*}\end{array}$ \\
\hline Sharma et al ${ }^{38}(2010)$ & Oral SCC & $\begin{array}{l}10 \text { of normal mucosa and } \\
30 \text { of cancer }\end{array}$ & $\begin{array}{l}\text { Vessels were stained } \\
\text { for vWF, and h-MVD } \\
\text { was measured using } \\
\text { the hotspot method }\end{array}$ & $\begin{array}{l}\text { h-MVD }\left(\mathrm{mm}^{-2}\right) \text { : normal } 64.4 \pm 13.53 \\
\text { and cancer } 240.53 \pm 92.3^{*}\end{array}$ \\
\hline $\begin{array}{l}\text { Mohtasham et } a^{39} \\
(2010)\end{array}$ & Oral SCC & $\begin{array}{l}6 \text { of normal mucosa, } \\
22 \text { of dysplasia, and } 42 \text { of } \\
\text { cancer }\end{array}$ & $\begin{array}{l}\text { Vessels were stained } \\
\text { for CD34, and h-MVD } \\
\text { was measured using } \\
\text { the hotspot method }\end{array}$ & $\begin{array}{l}\text { h-MVD }\left(\mathrm{mm}^{-2}\right): \text { normal } 27.5 \pm 12.5 \\
\text { dysplasia } 41.5 \pm 8.5, * \text { and cancer } \\
57.8 \pm 10.8^{*}\end{array}$ \\
\hline
\end{tabular}

Note: *Significantly different to normal tissue $(p<0.05)$.

Abbreviations: SCC, squamous cell carcinoma; h-MVD, highest microvascular density; RVV, relative vascular volume; vWF, von Willebrand factor.

margins of invasive regions. The same has been reported elsewhere. ${ }^{43} \mathrm{Li}$ et al also noted that the vessels in normal oral mucosa were regularly distributed and had regular courses and cross-sectional shapes, whereas at the margin of oral SCC, the vessels had irregular courses and elongated crosssectional shapes.

The method of differential path length spectroscopy used by Amelink et $\mathrm{al}^{44}$ also enabled measurement of the microvascular oxygen saturation $\left(\mathrm{StO}_{2}\right)$. They reported that the vessels were significantly less oxygenated in oral SCC than that in normal oral mucosa $(p<0.05)$, with $\mathrm{StO}_{2}$ values of $81 \pm 21$ and $95 \pm 5 \%$, respectively. They also found that this was the case for bronchial carcinoma compared with normal bronchial mucosa. ${ }^{45}$ These findings suggest that the tumors contained poorly perfused vessels and thus blood depleted of oxygen. 


\section{Effects of the tumor vasculature on the tumor microenvironment}

Ultimately, the tumor vasculature must be judged by how well it nourishes the tumor cells. In a study of surgical resections of human bronchial carcinoma, Thomlinson and Gray ${ }^{46}$ discovered how the vasculature in spontaneous human tumors sometimes fails in this sense. They found that the tumor cells were located in cords, where each cord had a single blood vessel along its axis and outside of the cords there was necrosis. The obvious explanation for their discovery was that the availability of oxygen and nutrients decreases with increasing distance from the blood vessels and only tumor cells within the cords were close enough to a blood vessel to survive. A similar corded structure was observed in Yamaura and Sato's chamber experiment, ${ }^{17}$ which was discussed in the first section of this review, but in that instance the cords appeared because only the largest vessels were still perfused after all of the smaller vessels had become occluded from the high interstitial pressure. In the present case, all of the vessels were perfused but apparently the vessel density was insufficient for the amount of oxygen available in the blood. Thomlinson and Gray recognized that there must be a large fraction of hypoxic cells in corded tumors, particularly in the outer regions of the cords bordering necrosis. Hypoxia of this nature is called "chronic hypoxia". It is sometimes misleadingly referred to as "diffusion limited". "Consumption limited" would be a more accurate term.

An example of an animal tumor that has an innate corded structure is the mouse mammary tumor BICR/SA1 studied by Tannock. ${ }^{47}$ Necrosis and cords of viable tissue were evident even in the smallest tumors examined weighing $0.1 \mathrm{~g}$. For tumors weighing between 0.5 and $3 \mathrm{~g}$, the relative necrotic volume was 60 to $70 \%$ and increased slightly with tumor weight. Tumor cords had radii in the range 60 to $120 \mu \mathrm{m}$, and there was no systematic variation in the mean cord radius with tumor weight. It was found that for animals breathing only $10 \%$ oxygen, the mean tumor cord radius decreased from $85.1 \pm 2.2$ to $75.5 \pm 8.8 \mu \mathrm{m}$. Tannock also investigated the patterns of cell proliferation in this tumor using tritiated thymidine. He found that proliferation in the tumor cords decreased with increasing distance from the blood vessels. He reported that this was due to a decrease in the fraction of cycling cells and that the cell cycle time did not vary. The growth fraction was $100 \%$ in the inner zone, $80 \%$ in the middle zone, and $50 \%$ in the outer zone of the cords. He noted that tumor cells must migrate centrifugally through the tumor cords. When a tumor cell divides, its daughter displaces neighboring cells further toward the cord periphery and finally into the necrotic zone. He suggested that for every tumor cell produced by mitosis, on average one tumor cell becomes necrotic (neglecting longitudinal cord growth). Therefore in tumor cords, there is constant cell renewal. It was estimated that cells in the inner and middle zones took 36 and 16 hours, respectively, to migrate to the outer zone.

A similar experiment was conducted by Hirst and Denekamp ${ }^{48}$ on the corded tumors of another transplantable mouse mammary carcinoma KHH. They reported that proliferation in this tumor did not vary between center and periphery, it only decreased with increasing distance from blood vessels. Unlike Tannock, they found that the cell cycle time did increase with increasing distance from the vessel, mainly due to the duration of the $G_{1}$ phase, which was 7.2 hours in the inner zone, 11.8 hours in the middle zone, and 17.1 hours in the outer zone. The growth fraction decreased from $100 \%$ in the inner and middle zones to $58 \%$ in the outer zone of the cords. They too estimated that a cell labeled next to a vessel transversed the $90 \mu \mathrm{m}$ to the outer zone in $\sim 36$ hours. In both this study and Tannock's study, it was estimated that the growth fraction in the outer zone of the cord, which neighbored the necrotic region and presumably contained hypoxic cells, was over $50 \%$. This large population of radioresistant cells with the ability to repopulate the tumor would make these tumors difficult to eradicate with radiotherapy.

More recently, the effects of the vasculature on the tumor microenvironment have been explored in human tumors, particularly those of head and neck cancers, by staining tumor sections with markers for blood vessels and hypoxia. Wijffels et $\mathrm{a}^{31}$ studied the spatial relationship between hypoxia and blood vessels in 22 specimens of human SCC of the oropharynx, larynx, and hypopharynx. Blood vessels were stained by Pathologische Anatomie Leiden-Endothelium (PAL-E), and hypoxia was stained by pimonidazole. Pimonidazole binding occurs at oxygen tensions less than $10 \mathrm{mmHg}$. ${ }^{49,50}$ The fraction of the tumor section stained by pimonidazole, called the hypoxic fraction, varied between 2 and $29 \%$ across the entire tumor surface. Of the 22 tumors, 16 had a total hypoxic fraction above $5 \%$. For these tumors, to quantitate the distribution of hypoxia in relation to the vasculature, the hypoxic fraction was calculated in zones at increasing distance from the nearest blood vessel $(0-50,50-100,100-150 \mu \mathrm{m}$, etc.). Accordingly, tumors were separated into three categories. One category of tumors had hypoxia between 50 and $200 \mu \mathrm{m}$ from vessels and small areas of necrosis beyond 150-200 $\mu \mathrm{m}$. These tumors possessed a typical corded structure (Figure 2). Another category of tumors had very little hypoxia within 


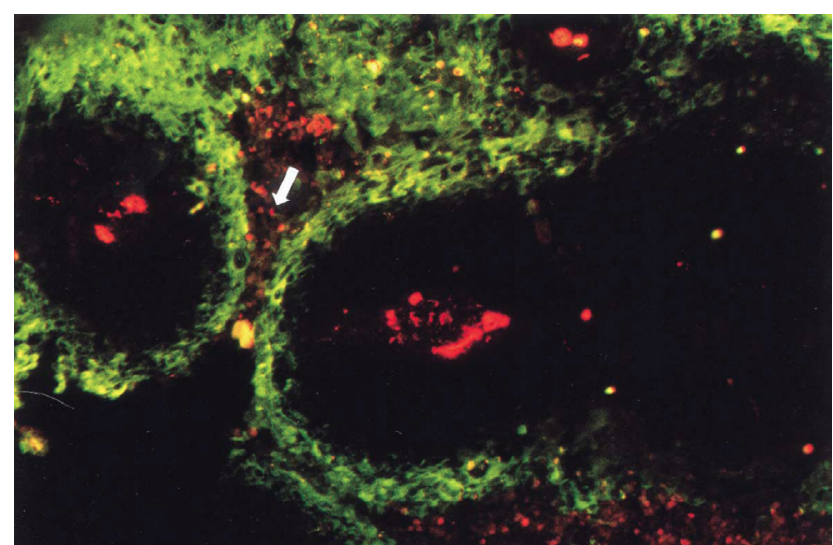

Figure 2 Fluorescence microscopic image of a tumor section after staining for hypoxia (green) and vessels (red).

Notes: A typical corded structure is recognizable. There are well-oxygenated areas directly adjacent to vessels, further out there is hypoxia and at even greater distances there is necrosis (white arrow). Adapted with permission from Macmillan Publishers Ltd on behalf of Cancer Research UK: British Journal of Cancer, Wijffels KIEM, Kaanders JHAM, Rijken PFJW, et al, Vascular architecture and hypoxic profiles in human head and neck squamous cell carcinomas, 2000;83(5):674-683, ${ }^{31}$ copyright 2000.

$100 \mu \mathrm{m}$ of vessels and significant amounts of viable, hypoxic tissue at distances greater than $200 \mu \mathrm{m}$. The stark contrast between these categories suggests that oxygen consumption and delivery varied considerably between tumors. In the last category, tumors had considerable amounts of hypoxia within $50 \mu \mathrm{m}$ of blood vessels, where there are ordinarily normoxic cells. Hypoxia this close to blood vessels is caused by a temporary absence of vessel perfusion and is termed "acute hypoxia" to distinguish it from consumption-limited, chronic hypoxia. In each category, the tumors showed an increase in the hypoxic fraction in zones at increasing distance from blood vessels (at least before the onset of necrosis).

An alternative hypoxia marker to pimonidazole is carbonic anhydrase 9 (CA9). CA9 is typically expressed at oxygen tensions less than $20 \mathrm{mmHg} .{ }^{51}$ Since it has a higher threshold than pimonidazole, it should stain closer to blood vessels. Hoogsteen et $\mathrm{al}^{52}$ found this was the case in a study of 103 human biopsies of laryngeal SCC. For 18 tumors of assorted human head and neck SCCs, Beasley et $\mathrm{a}^{53}$ found that the distance from blood vessels (stained by CD34) to the start of CA9 expression was between 40 and $140 \mu \mathrm{m}$ (median $80 \mu \mathrm{m})$ and the distance from blood vessels to the onset of necrosis was between 80 and $200 \mu \mathrm{m}$ (median $130 \mu \mathrm{m}$ ).

Further insights have been gained from staining tumor sections with markers for perfusion and proliferation in conjunction with markers for vessels and hypoxia. By staining vessels with 9F1, perfusion with Hoechst 33342, and proliferation with S-phase marker BrdUrd, Bussink et $\mathrm{al}^{54}$ showed that proliferation staining decreased in zones at increasing distance from both perfused and nonperfused vessels in xenografts of human laryngeal SCC grown subcutaneously in mice. Proliferation was higher near perfused than nonperfused vessels, but proliferation close to nonperfused vessels was comparable to or greater than it was at larger distances from perfused vessels. This indicated that the nonperfused vessels were recently perfused and thus vessel perfusion fluctuated in these tumors.

In a study of xenografts of human head and neck SCCs grown subcutaneously in mice, Ljungkvist et a ${ }^{55}$ found that different vasculature structures give rise to different distributions of hypoxia. By staining blood vessels with 9F1 and hypoxia with pimonidazole, two distinct patterns of hypoxia were identified. Patchy hypoxia was associated with a typical tumor cord structure. Ribbon-like hypoxia occurred when the vessels were in sheet structures that formed concentric lobe shapes. In both cases, the hypoxic fraction increased and proliferation staining with BrdUrd decreased in zones at increasing distance from blood vessels. They found that there was considerable overlap between hypoxia and proliferation, particularly at $100-150 \mu \mathrm{m}$ from vessels.

Some human head and neck cancers are well oxygenated. Wijffels et a ${ }^{56}$ conducted a study of eight specimens of human salivary gland carcinoma and found that none contained any hypoxia according to staining with pimonidazole and CA9. They also stained blood vessels with PAL-E, and it was apparent that the MVD was high across the entire tumor sections. The a-MVD varied from 209 to $546 \mathrm{~mm}^{-2}$ (median $285 \mathrm{~mm}^{-2}$ ). There were no measurements on normal tissue to compare with, but they reported in the aforementioned study of oropharyngeal, laryngeal, and hypopharyngeal SCCs (again staining vessels with PAL-E) that the a-MVD varied between 11 and $67 \mathrm{~mm}^{-2}$ (median $42 \mathrm{~mm}^{-2}$ ). Assuming they used similar methodologies between studies, it is safe to conclude that these salivary gland carcinomas were extremely vascularized. Along with the lack of hypoxia, there was no clear spatial relationship between proliferation staining with IdUrd (another S-phase marker) and vessel structures.

\section{Conclusion}

Studies of tumor transplants growing subcutaneously in rats and mice reveal that the tumor vasculature develops inefficiently under the imbalance of angiogenic regulators. The tumor vessels are unorganized and become increasingly tortuous and disfigured, hindering vessel perfusion. When tumors become large, high interstitial fluid pressures can develop, which cause vessels in the tumor to permanently shut, resulting in blood stasis and the development of macroscopic necrosis. 
Data from spontaneous human head and neck cancers show that there are typically regions in the tumor that are more vascularized than any region in the normal tissue. Although the data are limited, it seems that tumors are also more vascularized overall. This is not trivial - the opposite has been reported for esophageal $\mathrm{SCC}^{57}$ and lung cancer. ${ }^{58}$ However, tumor vascularity is highly heterogeneous, and there can still be regions of head and neck cancers, in which the vascularity is comparable to or even less than that in normal tissue. Vascular hotspots are most commonly observed in invasive regions of the carcinoma. Like in animal models, the vessels in spontaneous human carcinomas are observed to be irregular and tortuous compared to those in the normal tissue, thus hindering perfusion and reducing the oxygenation levels in the blood, as evidenced by $\mathrm{StO}_{2}$ measurements.

By staining tumor sections of head and neck cancers with markers for vessels, perfusion, hypoxia, and proliferation, it becomes apparent that the tumor vasculature intimately shapes the microenvironment. Acute hypoxia is observed near vessels that were not recently perfused (though perfusion fluctuates and the acute hypoxia soon moves elsewhere), and chronic hypoxia is observed at a distance from perfused blood vessels. Chronic hypoxia according to staining of pimonidazole began at distances between 75 and $125 \mu \mathrm{m}$ from vessels, while chronic hypoxia according to CA9 expression began at distances between 40 and $140 \mu \mathrm{m}$ from vessels, with the difference largely reflecting their different oxygen tension thresholds for binding and expression. The distance from blood vessels to the onset of necrosis varied from 80 to $300 \mu \mathrm{m}$. The distance from blood vessels to the onset of chronic hypoxia, observed by staining or expression of a hypoxic marker, depends on the blood oxygenation and the metabolic demands of the tumor cells. The distance from blood vessels to the onset of necrosis depends on these factors and the tolerance of the tumor cells to hypoxia. Chronic hypoxia and necrosis are observed closer to vessels in tumors than in normal tissue because the blood oxygenation is less in tumors, and tumor cells typically have increased metabolic demands. Thus, the vascular density in the tumor does not need to be less than that in normal tissue for chronic hypoxia to occur.

In practice, acute hypoxia and chronic hypoxia are limited to the least vascularized regions of tumors for head and neck cancers. In these regions, there was an increase in staining of hypoxia markers and a corresponding decrease in staining of proliferation markers with increasing distance from the vessels. Microscopic regions of necrosis were also observed at large distances from vessels. The decrease in proliferation may possibly be attributed to a decreasing growth fraction (as hypoxic cells are held up at cell cycle checkpoints) and lengthening of the duration of the $G_{1}$ phase of the cell cycle. Thus, tumor cells become more radioresistant further from the vessels as more of them are hypoxic and more are found in the relatively radioresistant $G_{1}$ phase. Contrastingly, in vascular hotspots, there was little hypoxia staining and no clear spatial relationship between proliferation staining and the vessels.

Since the morphology of the tumor vasculature strongly affects the tumor microenvironment, the tumor vasculature should ideally be included in models that simulate tumor growth and tumor response to irradiation. This is especially necessary when modeling poorly oxygenated tumors like those of head and neck cancers. Such radiotherapy models are highly valuable for their insight, utility, and predictive powers. They may be used to determine the most effective radiotherapy treatment schedule for a given set of tumor properties. It is hoped they will lead to better customization of radiotherapy treatment plans on an individual patient basis by accounting for interpatient variations in tumor properties. Indeed, some radiotherapy models have been developed that include a basic representation of the tumor vasculature, ${ }^{59,60}$ but since the vasculature can have such a strong effect, it is important that it be modeled as realistically as possible. Accurate simulation of the tumor vasculature will also be important in exploring and optimizing vascular targeting treatment techniques. It is hoped that the quantitative vasculature morphology data compiled within will assist with the modeling efforts to come.

\section{Disclosure}

The authors report no conflicts of interest in this work.

\section{References}

1. Gimbrone MA Jr, Leapman SB, Cotran RS, Folkman J. Tumor dormancy in vivo by prevention of neovascularization. J Exp Med. 1972;136(2):261-276.

2. Pilat MJ, McCormick J, LoRusso PM. Vascular targeting agents. Curr Oncol Rep. 2004;6(2):103-110.

3. Park HJ, Griffin RJ, Hui S, et al. Radiation-induced vascular damage in tumors: implications of vascular damage in ablative hypofractionated radiotherapy (SBRT and SRS). Radiat Res. 2012;177(3):311-327.

4. El Kaffas A, Giles A, Czarnota GJ. Dose-dependent response of tumor vasculature to radiation therapy in combination with sunitinib depicted by three-dimensional high-frequency power Doppler ultrasound. Angiogenesis. 2013;16(2):443-454.

5. Franks KN, Jain P, Snee MP. Stereotactic ablative body radiotherapy for lung cancer. Clin Oncol (R Coll Radiol). 2015;27(5):280-289.

6. Musunuru HB, Loblaw A. Clinical trials of stereotactic ablative radiotherapy for prostate cancer: updates and future direction. Future Oncol. 2015;11(5):819-831.

7. Karam SD, Bhatia S. The radiobiological targets of SBRT: tumor cells or endothelial cells? Ann Transl Med. 2015;3(19):290. 
8. Allen BJ, Huang C-Y, Clarke RA. Targeted alpha anticancer therapies: update and future prospects. Biologics. 2014;4(8):255-267.

9. Butterworth KT, McMahon SJ, Currell FJ, Prise KM. Physical basis and biological mechanisms of gold nanoparticle radiosensitization Nanoscale. 2012;4(16):4830-4838.

10. Lin Y, Paganetti H, McMahon SJ, Schuemann J. Gold nanoparticle induced vasculature damage in radiotherapy: comparing protons, megavoltage photons, and kilovoltage photons. Med Phys. 2015;42(10):5890-5902.

11. Becker A, Hänsgen G, Bloching M, Weigel C, Lautenschläger C, Dunst J. Oxygenation of squamous cell carcinoma of the head and neck: comparison of primary tumors, neck node metastases, and normal tissue. Int J Radiat Oncol Biol Phys. 1998;42(1):35-41.

12. Algire GH, Chalkley HW. Vascular reactions of normal and malignant tissues in vivo. I. Vascular reactions of mice to wounds and to normal and neoplastic transplants. $J$ Natl Cancer Inst. 1945;6(1):73-85.

13. Folkman J. Tumor angiogenesis. Adv Cancer Res. 1985;43(1):175-203.

14. Chalkley HW. Method for the quantitative morphologic analysis of tissues. J Natl Cancer Inst. 1943;4(1):47-53.

15. Jain RK. Molecular regulation of vessel maturation. Nat Med. 2003;9(6):685-693.

16. Eddy HA, Casarett GW. Development of the vascular system in the hamster malignant neurilemmoma. Microvasc Res. 1973;6(1):63-82.

17. Yamaura H, Sato H. Quantitative studies on the developing vascular system of rat hepatoma. J Natl Cancer Inst. 1974;53(5):1229-1240.

18. Peters W, Teixeira M, Intaglietta M, Gross JF. Microcirculatory studies in rat mammary carcinoma. I. Transparent chamber method, development of microvasculature, and pressures in tumor vessels. J Natl Cancer Inst. 1980;65(3):631-642.

19. Boucher Y, Leunig M, Jain RK. Tumor angiogenesis and interstitial hypertension. Cancer Res. 1996;56(18):4264-4266.

20. Endrich B, Hammersen F, Götz A, Messmer K. Microcirculatory blood flow, capillary morphology, and local oxygen pressure of the hamster amelanotic melanoma A-Mel-3. J Natl Cancer Inst 1982;68(3):475-485.

21. Vajkoczy P, Schilling L, Ullrich A, Schmiedek P, Menger MD. Characterization of angiogenesis and microcirculation of high-grade glioma: an intravital multifluorescence microscopic approach in the athymic nude mouse. J Cereb Blood Flow Metab. 1998;18(5):510-520.

22. Leu AJ, Berk DA, Lymboussaki A, Alitalo K, Jain RK. Absence of functional lymphatics within a murine sarcoma: a molecular and functional evaluation. Cancer Res. 2000;60(16):4324-4327.

23. Goldacre RJ, Sylven B. On the access of blood-borne dyes to various tumour regions. Br J Cancer. 1962;16(1):306-322.

24. Tozer GM, Lewis S, Michalowski A, Aber V. The relationship between regional variations in blood flow and histology in a transplanted rat fibrosarcoma. Br J Cancer. 1990;61(2):250-257.

25. Tannock IF, Steel GG. Quantitative techniques for study of the anatomy and function of small blood vessels in tumors. $J$ Natl Cancer Inst. 1969;42(5):771-782.

26. Fallowfield ME. Vascular volume in B16 allografts and human melanoma xenografts estimated by means of Hoechst 33342. J Pathol. 1989;157(3):249-252.

27. Rubin P, Casarett G. Microcirculation of tumors part I: anatomy, function, and necrosis. Clin Radiol. 1966;17(3):220-229.

28. Deane BR, Lantos PL. The vasculature of experimental brain tumours. Part 1. A sequential light and electron microscope study of angiogenesis. J Neurol Sci. 1981;49(1):55-66.

29. Vogel AW. Intratumoral vascular changes with increased size of a mammary adenocarcinoma: new method and results. $J$ Natl Cancer Inst. 1965;34(5):571-578.

30. Hilmas DE, Gillette EL. Morphometric analyses of the microvasculature of tumors during growth and after $\mathrm{x}$-irradiation. Cancer. 1974;33(1):103-110.

31. Wijffels KIEM, Kaanders JHAM, Rijken PFJW, et al. Vascular architecture and hypoxic profiles in human head and neck squamous cell carcinomas. Br J Cancer. 2000;83(5):674-683.
32. Pazouki S, Chisholm DM, Adi MM, et al. The association between tumour progression and vascularity in the oral mucosa. $J$ Pathol. 1997;183(1):39-43.

33. Sawatsubashi M, Yamada T, Fukushima N, Mizokami H, Tokunaga O, Shin T. Association of vascular endothelial growth factor and mast cells with angiogenesis in laryngeal squamous cell carcinoma. Virchows Arch. 2000;436(3):243-248.

34. Pignataro L, Carboni N, Midolo V, et al. Clinical relevance of microvessel density in laryngeal squamous cell carcinomas. Int $J$ Cancer. 2001;92(5):666-670.

35. Shieh YS, Lee HS, Shiah SG, Chu YW, Wu CW, Chang LC. Role of angiogenic and non-angiogenic mechanisms in oral squamous cell carcinoma: correlation with histologic differentiation and tumor progression. J Oral Pathol Med. 2004;33(10):601-606.

36. Li C, Shintani S, Terakado N, et al. Microvessel density and expression of vascular endothelial growth factor, basic fibroblast growth factor, and platelet-derived endothelial growth factor in oral squamous cell carcinomas. Int J Oral Maxillofac Surg. 2005;34(5):559-565.

37. Shieh YS, Hung YJ, Hsieh CB, Chen JS, Chou KC, Liu SY. Tumorassociated macrophage correlated with angiogenesis and progression of mucoepidermoid carcinoma of salivary glands. Ann Surg Oncol. 2009;16(3):751-760.

38. Sharma B, Sriram G, Saraswathi TR, Sivapathasundharam B. Immunohistochemical evaluation of mast cells and angiogenesis in oral squamous cell carcinoma. Indian J Dent Res. 2010;21(2):260-265.

39. Mohtasham N, Babakoohi S, Salehinejad J, et al. Mast cell density and angiogenesis in oral dysplastic epithelium and low- and high-grade oral squamous cell carcinoma. Acta Odontol Scand. 2010;68(5):300-304.

40. Weidner N, Semple JP, Welch WR, et al. Tumor angiogenesis and metastasis - correlation in invasive breast carcinoma. $N$ Engl $J$ Med. 1991;324(1):1-8.

41. Davey KJ, Perrier S, Ohe G, et al. Assessment of vascularity as an index of angiogenesis in periradicular granulomas. Comparison with oral carcinomas and normal tissue counterparts. Int Endod $J$. 2008;41(11):987-996.

42. Schor AM, Pendleton N, Pazouki S, et al. Assessment of vascularity in histological sections: effects of methodology and value as an index of angiogenesis in breast tumours. Histochem J. 1998;30(12):849-856.

43. Hagedorn HG, Nerlich AG. Microvessel density and endothelial basement membrane composition in laryngeal squamous cell carcinomas. Acta Otolaryngol. 2000;120(7):891-898.

44. Amelink A, Kaspers OP, Sterenborg HJ, van der Wal JE, Roodenburg JL, Witjes MJ. Non-invasive measurement of the morphology and physiology of oral mucosa by use of optical spectroscopy. Oral Oncol. 2008;44(1):65-71.

45. Amelink A, Sterenborg HJ, Bard MP, Burgers SA. In vivo measurement of the local optical properties of tissue by use of differential path-length spectroscopy. Opt Lett. 2004;29(10):1087-1089.

46. Thomlinson RH, Gray LH. The histological structure of some human lung cancers and the possible implications for radiotherapy. Br JCancer. 1955;9(4):539-549.

47. Tannock IF. The relation between cell proliferation and the vascular system in a transplanted mouse mammary tumour. $\mathrm{Br} J$ Cancer. 1968;22(2):258-273.

48. Hirst DG, Denekamp J. Tumour cell proliferation in relation to the vasculature. Cell Tissue Kinet. 1979;12(1):31-42.

49. Gross MW, Karbach U, Groebe K, Franko AJ, Mueller-Klieser W. Calibration of misonidazole labeling by simultaneous measurement of oxygen tension and labeling density in multicellular spheroids. Int $J$ Cancer. 1995;61(4):567-573.

50. Chou SC, Azuma Y, Varia MA, Raleigh JA. Evidence that involucrin, a marker for differentiation, is oxygen regulated in human squamous cell carcinomas. Br J Cancer. 2004;90(3):728-735.

51. Wykoff CC, Beasley NJ, Watson PH, et al. Hypoxia-inducible expression of tumor-associated carbonic anhydrases. Cancer Res. 2000;60(24):7075-7083. 
52. Hoogsteen IJ, Lok J, Marres HA, et al. Hypoxia in larynx carcinomas assessed by pimonidazole binding and the value of CA-IX and vascularity as surrogate markers of hypoxia. Eur $J$ Cancer. 2009;45(16):2906-2914.

53. Beasley NJ, Wykoff CC, Watson PH, et al. Carbonic anhydrase IX, an endogenous hypoxia marker, expression in head and neck squamous cell carcinoma and its relationship to hypoxia, necrosis, and microvessel density. Cancer Res. 2001;61(13):5262-5267.

54. Bussink J, Kaanders JH, Rijken PF, Martindale CA, van der Kogel AJ. Multiparameter analysis of vasculature, perfusion and proliferation in human tumour xenografts. Br J Cancer. 1998;77(1):57-64.

55. Ljungkvist AS, Bussink J, Rijken PF, Kaanders JH, van der Kogel AJ, Denekamp J. Vascular architecture, hypoxia, and proliferation in first-generation xenografts of human head-and-neck squamous cell carcinomas. Int J Radiat Oncol Biol Phys. 2002;54(1):215-228.
56. Wijffels KIEM, Hoogsteen IJ, Lok J, et al. No detectable hypoxia in malignant salivary gland tumors: preliminary results. Int J Radiat Oncol Biol Phys. 2009;73(5):1319-1325.

57. Porschen R, Classen S, Piontek M, Borchard F. Vascularization of carcinomas of the esophagus and its correlation with tumor proliferation. Cancer Res. 1994;54(2):587-591.

58. Schor AM, Pazouki S, Morris J, Smither RL, Chandrachud LM, Pendleton N. Heterogeneity in microvascular density in lung tumours: comparison with normal bronchus. Br J Cancer. 1998;77(6):946-951.

59. Borkenstein K, Levegrun S, Peschke P. Modeling and computer simulations of tumor growth and tumor response to radiotherapy. Radiat Res. 2004;162(1):71-83.

60. Harting C, Peschke P, Borkenstein K, Karger CP. Single-cell-based computer simulation of the oxygen-dependent tumour response to irradiation. Phys Med Biol. 2007;52(16):4775-4789.

\section{Hypoxia}

\section{Publish your work in this journal}

Hypoxia is an international, peer-reviewed, open access journal that aims to improve understanding of the biological response to hypoxia. The journal will publish original research articles, reviews, methodological advances, clinical studies, and expert opinions that identify developments in the regulation of the physiological and pathological responses to

Submit your manuscript here: https://www.dovepress.com/hypoxia-journal

\section{Dovepress}

hypoxia and in the therapeutic targeting of hypoxia-responsive pathways The manuscript management system is completely online and includes a very quick and fair peer-review system, which is all easy to use. Visit http://www.dovepress.com/testimonials.php to read real quotes from published authors. 